\section{The Impact of Coping Strategies and Social Support on the Experience of Stress in High Performance Athletes}

\author{
Lavinia McLean* and Rebecca Penco \\ Technological University Dublin, Blanchard town, Dublin 15, Ireland
}

\begin{abstract}
Stress is an unavoidable part of all our lives and can have a significant impact on many elements of a person's wellbeing. While there is evidence of the benefit of involvement in sport and physical activity, elite athletes face additional stressors on a frequent basis. Substantial research has indicted the importance of effective coping strategies to allow athletes to limit the impact of these stressors. The current study adopted a quantitative approach to assess the impact of coping strategies and perceived social supports on the level of stress in a sample $(n=124)$ of high performance athletes in Ireland.

The findings indicated that the most frequently used coping strategies were the task focused ones and in particular cognitive focused strategies, including the use of thought control, mental imagery and logical analysis. There was a significant correlation between the experience of stress and the use of these task focused strategies, similar to previous research. High performance athletes experienced a moderate level of stress, with lower levels of stress associated with higher levels of perceived social support. Informational support was identified as most significant in terms of impact on levels of stress. This type of support may address organisational stressors which have previously been identified as the most significant cause of stress for high performance athletes. The results are discussed in relation to recommendations for managing stress effectively in athletes, non athletes and future research needed to extend the findings.
\end{abstract}

Keywords: Coping startegies; High performance athletes; Social support; Stress

"Corresponding author: Lavinia McLean, Technological University Dublin, Blanchard town, Dublin 15, Ireland, Tel: +353 018851185; E-mail: lavinia.mclean@tudublin.ie

Citation: McLean L, Penco R (2020) The Impact of Coping Strategies and Social Support on the Experience of Stress in High Performance Athletes. $J$ Addict Addictv Disord 7: 43.

Received: May 07, 2020; Accepted: May 22, 2020; Published: May 30, 2020

Copyright: @ 2020 McLean L, et al. This is an open-access article distributed under the terms of the Creative Commons Attribution License, which permits unrestricted use, distribution, and reproduction in any medium, provided the original author and source are credited.

\section{Introduction}

While for some people the experience of stress can be positively viewed as a challenge, the experience can be overwhelming at times. In a recent review Slavich [1], highlighted the extensive research on the impact of stress on physical and mental health on young people, adults and clinical populations. It is now generally accepted that a positive relationship exists between engagement in regular exercise and physical and mental wellbeing [2], including the ability to coping with stress. It is interesting to consider the impact of extensive engagement in physical exercise, such as with athletes. Athletes represent a specific cohort of individuals that submerge themselves in an environment where stress is inevitable and this is even more significant for high performance or professional athletes [3]. Recent studies have indicated that up to half of high performance athletes have reported extensive levels of stress [3-5], with athletes who experienced elevated levels of stress at a higher risk of burnout [6].

High performance athletes are particularly committed individuals that submerge themselves in an environment where stress is a constant [6]. These athletes experience incredible pressure to succeed, endure a strict lifestyle and intensive training [4]. They must therefore learn to effectively manage the stressors within their sport, but also within their daily lives. For the high performance athlete every competition has a significant impact but there are mixed findings in relation to whether higher stressors are experienced during competition $[7,8]$ or within in training [9-11]. Regardless of the setting, the majority of these stressors can be organised under three main headings, personal, organisational and competition. There is some indication that organisational demands caused greater stress than the competition demands $[12,13]$.

In terms of internal stressors, athletes have reported sources of stress stemming from performance expectations [14], fear of making mistakes $[10,11,15,16]$, fear of failure, [17] or of injury [11]. The size and significance of the competition has been found to impact the levels of stress experienced and this is particularly relevant for inexperienced athletes [12]. Athletes have reported additional personal stressors arising due to managing time and sport related demands $[17,18]$ and associated tiredness [11,19]. Financial concerns have recently been highlighted as a source of stress, for athletes [20], which may be related to the reduced length of careers for high performance athletes [21].

The literature suggests that in addition to individual stressors, external factors may have an impact on the experience of stress for athletes. Environmental conditions can act as a source of stress for athletes during training and competition [17], including weather conditions $[22,23]$ and the impact of these on athlete and on official's decision making. In terms of type of sport played, there is some indication that the sport settings may play a role in the experience and management of stress. Athletes that are involved in sports such as football and basketball are often described as open skilled athletes, who compete in an environment that is constantly changing, requiring athletes to constantly change their strategies and as such deal more 
Citation: McLean L, Penco R (2020) The Impact of Coping Strategies and Social Support on the Experience of Stress in High Performance Athletes. J Addict Addictv Disord 7: 43.

effectively with stress [24]. Spectators and the officials have been highlighted as a significant cause of stress $[10,25,26]$. Relationships with others within and outside of sport are also reported to be a significant cause of stress for athletes, with some indication that athletes may experience higher levels of stress from relationships than non-athletes [19]. In particular relationship and interactions with those within the organisation, such as coaches and other athletes have been highlighted as contributors to the experience of stress $[25,27,28]$.

The intense physical, psychological and emotional demands on these athletes requires that they develop and use an array of effective coping strategies to meet these needs. The way that an athlete evaluates and copes with the demands of their sport has been shown to have a significant impact on their performance, in addition to their overall wellbeing. The literature consistently groups these coping strategies into two main categories, namely task oriented coping, including concentrating on goals, time management, learning about opponents and practice during training and avoidant oriented coping, including mental withdrawal, avoiding and distancing oneself from the stressor. Research with elite athletes has found that task focused coping are the most effective strategies to deal with stressors that are appraised as being threat or harm related or a significant challenge [14]. Similar findings have been reported to lead to an increased ability to manage stressors [29,30], including concentration and positive reappraisal [31], rationalizing, reappraising and positive self-talk [22]. Athletes who use approaches involving control over their mind-set have been shown to more successfully manage stress, including use of visualization techniques [15,32]. Developing an understanding of their own thought process, including their thoughts, feelings and actions [18] and the use of mindfulness has been identified as a significant coping mechanism for managing stress effectively $[16,33]$.

Relationships which provide social support have been identified as having an essential influence on an athlete's wellbeing and success [34]. These specific sports related relationships and related forms of social support are particularly important to understand as they are unique to athletes. Importantly, for athletes the research suggests that social support from coaches, teammates, family, friends and the organisation is considered to affect an athlete's cognitive, emotional and behavioural aspects of their life in a positive and a negative manner. Social support has also been found to be correlated with athlete's view of their competitive experiences as a challenge rather than a threat [35]. Perceived social support has been argued to have the potential to provide a buffer in times of stress, to increase happiness and enhance overall psychological wellbeing [36-39]. The literature suggests that athlete perceptions of social support may be potential moderators of both the perceived stress-burnout and athlete burnout-well-being relationships [40]. Social support has also been suggested as reducing the perception of stress and depression [41] and the negative factors that lead to athletic burnout $[42,43]$.

Crutcher et al. [41], found that social satisfaction in terms of support from family and other athletic trainers were significant predictors of perceived stress, while teammates have been identified as the most positive aspect of athletic involvement. Defreese and Smith [44], suggest that an athlete's perception of available support from teammates is important to reduce the risk of athlete burnout. In terms of type of stressors, social support has been argued to positively impact on the athlete's ability to deal effectively with both competitive stressors [45] and organizational stressors [12]. Recent research conducted suggests that informational and emotional support were crucial when dealing with competitive stress, while tangible support was more important for allowing athletes to manage and deal effectively with organizational stressors [12].

High performance athletes can be seen as a group who are particularly driven and motivated, in addition to facing a significant number of stressors. Further to this, the impact of not effectively managing this stress can lead to a significant impact both personally and professionally for these athletes. The current research was therefore designed to explore the ability of this group of specialised athletes to manage stress within their sporting life. The literature has also consistently identified one of the main categories of stressors for these athletes as organisational stressors and the current research was interested in identifying any impact of specific coping strategies and social support to would allow for the effective management of this category of stressors. The three hypothesis for the research are:

\section{Hypothesis 1}

High-performance athletes will report moderate to high levels of perceived stress.

\section{Hypothesis 2}

There will be a negative relationship between task orientated coping strategies and reported stress, with athletes who report lower stress engaged in task orientated coping strategies.

\section{Hypothesis 3}

There will be a negative relationship between informational social support and reported stress, with athletes who report lower stress reporting higher levels of informational social support.

\section{Methodology}

\section{Sample}

The participants in the current study were high performance athletes $(n=124)$ who were currently competing in team sports in Ireland at the highest level in their respective sport. In total athletes from eight different teams participated in the research. The performance level of the participants ranged from those that competed at county level $(n=83)$ and international level $(n=41)$. Sixty-two males and sixty-two females were included in the final analysis of this study. The participant's ages ranged from 18 to 32 years.

\section{Research instruments}

This study combined a brief demographic questionnaire followed by three surveys, The Perceived Stress Scale [46] and the Perceived Available Support in Sports Questionnaire and The Coping Inventory for Competitive Sports [47].

\section{Demographic questionnaire}

For the social support scale, the participants were asked to consider the last competitive match they had played, to identify whether they won or lost this match and to use this experience to answer the questions in each of the scales. The other demographic questions included identifying their gender, age, the sport played by the participant and length of time playing the sport at their current level. 
Citation: McLean L, Penco R (2020) The Impact of Coping Strategies and Social Support on the Experience of Stress in High Performance Athletes. J Addict Addictv Disord 7: 43.

\section{Coping Inventory for Competitive Sports (CICS)}

The Coping Inventory for Competitive Sports [47], which is a sports specific measure, developed to measure coping strategies used by athletes in sports competitions, both in their preparation for the sports competition and during the sports competition [47]. The CICS is a 39 item, self-report instrument with each item representing things that athletes can do or think before or during a sports competition, for example 'I visualized that I was in total control of the situation'. In total the scale measures ten coping strategies (mental imagery, effort expenditure, thought control, relaxation, logical analysis, seeking support, distancing, mental distraction, disengagement and venting of unpleasant emotions). Each strategy is represented by four items on the questionnaire.

The questionnaire is rated on a five-point Likert scale. Following each question participants must select the answer that most accurately reflects their own opinion of what they did or thought before or during a sports competition. Answers range from ( $1=$ Not at all, 2=A little, $3=$ Moderately, $4=$ Strongly and $5=$ Very Strongly). Reliability has been reported for the scale ranged between $0.49-0.82$ for the 10-factor model and 0.75-0.82 for the three higher order dimensions. Nicholls et al. [15], showed reliability for the 3 higher order dimension level as follows, task (0.87), distraction (0.73) and disengagement-orientated coping (0.82).

\section{The Perceived Stress Scale (PSS)}

The PSS was designed to identify the level of perceived stress for each of the HPA and to determine the category of stress the athlete's scores are located within, low, medium or high perceived stress. The instrument is designed to measure how unpredictable, uncontrollable and overloaded individuals find their lives, three aspects that influence the experience of stress [48]. The 10-item self-report instrument contains ten items that when summed will determine how stressful a participant feel that their life is. Questions are asked about feelings and thoughts of participants during the last month and participants are asked to reply how often they have felt or thought a certain way depending on the question e.g., "In the last month, how often have you felt nervous and "stressed?", "In the last month, how often have you been upset because of something that happened unexpectedly" [48]. Responses are rated on a 5-point Likert- scale. Following each question participants must select the answer that most accurately reflects their own opinion of their feelings and thoughts. The scales responses range from $0=$ never, $1=$ almost never, $2=$ Sometimes, $3=$ fairly often and $4=$ very often, with an overall score ranging from 0 to 40 for the ten items. Cohen et al. [48], has reported good construct validity for the scale, Cronbach's alpha to be $>0.70$ and test-retest reliability $>0.70$ across twelve studies with adult populations.

\section{The Perceived Available Support in Sports Questionnaire (The PASS-Q)}

PASS-Q is a sport specific measure of perceived social support [43], is a self-report, sixteen item instrument that assesses four dimensions of social support including emotional, esteem, informational and tangible. Each dimension is represented by four questions and each question is worded in such a way to indicate the extent to which the participant perceives the support to be available to them at the time asked. An example of questions in the scale are "If needed, to what extent would someone, provide you with comfort and security, help you with travel to training and matches and give you advice when you're performing poorly". Following each question participants must select the answer that most accurately reflects their own opinion. Answers range from $0=$ not at all, $1=$ slightly, $2=$ moderately, $3=$ considerably and $4=$ extremely. Freeman et al. [43], support for the four-factor structure and the concurrent validity of the PASS-Q Freeman et al. [43]

\section{Procedure}

Fourteen sports teams were approached to participate in the study. Gatekeepers (managers of teams) were initially contacted by email. Participants were then asked if they wished to participate by their manager and it was the researcher that explained the outline of the study a brief summary of the requirements. All participants were ensured that participation was voluntary were given an information sheet and consent forms. Participants completed the demographic questionnaire followed by PASS-Q, CICS and the PSS. Participants were asked to complete the questionnaire as honestly as possible and were encouraged to ask for assistance with any difficulties that they had whilst completing the questionnaire. Once athletes had completed the questionnaire, they were asked to place their questionnaire in an envelope which was provided for them and thanked for their participation. There were no issues with the questionnaire once it was administered and none of the athletes chose to withdraw or to not continue once they had commenced completing the questionnaire.

\section{Analysis}

124 high performance athletes participated in the study and played one of four categories of team sports with the majority $(n=58)$ stating that they played GAA. Table 1 outlines the frequency of category of sport played (GAA, Camogie, Rugby, Soccer).

\begin{tabular}{|c|c|c|c|}
\hline & $\mathbf{n}$ & Male & Female \\
\hline GAA & 83 & 21 & 62 \\
\hline Rugby & 3 & 3 & 0 \\
\hline Soccer & 38 & 38 & 0 \\
\hline Total & 124 & 62 & 62 \\
\hline
\end{tabular}

Table 1: Type of competitive game played by respondents.

Hypothesis 1: Athletes will report moderate to high level of perceived stress

The results indicated that the majority of the participants reported scores in the moderate level of perceived stress $(M=18.75, S D=5.59)$. An independent t-test was conducted to compare stress levels for male and female participants. Male athletes $(\mathrm{M}=16.77, \mathrm{SD}=4.02)$ had significantly lower PSS scores that female athletes (M=20.73, SD 6.22: $\mathrm{t}(124)=4.2, \mathrm{p}<0.0005$ (two-tailed) (Table 2).

\begin{tabular}{|c|c|c|c|c|}
\hline Perceived Stress & n & Males & Female & Total Perceived Stress \\
\hline Athletes & 124 & 16.77 & 20.73 & 18.75 \\
\hline \multicolumn{5}{|c|}{ Table 2: Athletes perceived stress score. }
\end{tabular}

Hypothesis 2: Athletes who report higher use of task focused coping strategies will report lower levels of perceived stress 
Citation: McLean L, Penco R (2020) The Impact of Coping Strategies and Social Support on the Experience of Stress in High Performance Athletes. J Addict Addictv Disord 7: 43.

Table 3 outlines the mean scores for the ten coping strategies used by high performance athletes. Thought control strategy was most commonly used by respondents $(\mathrm{M}=14.16, \mathrm{SD}=2.9)$. Disengagement was the least reported strategy used by the respondents $(\mathrm{M}=7.1$, $\mathrm{SD}=3.17$ ).

\begin{tabular}{|c|c|c|c|}
\hline & Category & Overall Mean & S.D \\
\hline Thought control & Task & 14.16 & 2.89 \\
\hline Mental imagery & Task & 13.98 & 3.18 \\
\hline Logical analysis & Task & 13.58 & 3.13 \\
\hline Effort expenditure & Task & 12.56 & 2.29 \\
\hline Relaxation & Task & 11.71 & 3.72 \\
\hline Venting & Avoidant & 10.63 & 4.06 \\
\hline Seeking support & Task & 9.56 & 3.53 \\
\hline Mental distraction & Avoidant & 8.79 & 3.67 \\
\hline Distancing & Avoidant & 8.43 & 2.49 \\
\hline Disengagement & Avoidant & 7.09 & 3.17 \\
\hline \multicolumn{2}{|c|}{ Table 3: Mean }
\end{tabular}

Table 3: Mean scores for the 10 coping strategies.

The relationship between perceived stress (as measured by the PSS) and coping strategies (as measured by the CICS) was investigated using Pearson product-moment correlation coefficient. There was a medium negative correlation between mental imagery coping strategy and perceived stress, $r=-0.283, n=124, p<0.001$ and between effort expenditure coping strategy and perceived stress, $r=-0.296, n=124$, $\mathrm{p}<0.001$ and between thought control coping strategy and perceived stress, $\mathrm{r}=-0.291, \mathrm{n}=124, \mathrm{p}<0.001$ and between logical analysis coping strategy and perceived stress, $\mathrm{r}=-0.201, \mathrm{n}=124, \mathrm{p}<0.05$.

Hypothesis 3: Athletes who report higher levels of informational support will report lower levels of perceived stress

Table 4 outlines the mean perceived social support scores for high performance athletes. Emotional support was reported by the respondents as the type of social support most frequently available to the athletes $(\mathrm{M}=13.25, \mathrm{SD}=2.84)$ while tangible support was reported least available to the athletes $(\mathrm{M}=11.25, \mathrm{SD}=3.16)$.

\begin{tabular}{|c|c|c|c|c|}
\hline & Gender & $\mathbf{N}$ & Mean & Std. Deviation \\
\hline \multirow{2}{*}{ Emotional } & Male & 62 & 13.22 & 2.92 \\
& Female & 62 & 13.29 & 2.78 \\
\hline \multirow{2}{*}{ Esteem } & Male & 62 & 12.54 & 2.80 \\
& Female & 62 & 11.87 & 2.92 \\
\hline \multirow{2}{*}{ Information } & Male & 62 & 12.61 & 2.60 \\
& Female & 62 & 11.96 & 3.34 \\
\hline \multirow{2}{*}{ Tangible } & Male & 62 & 10.93 & 3.22 \\
& Female & 62 & 11.56 & 3.10 \\
\hline
\end{tabular}

Table 4: The mean perceived social support scores for male and female athletes.

The relationship between perceived social support (as measured by the PASS-Q) and perceived stress (as measured by the PSS) was investigated using the Pearson product-moment correlation coefficient. There was a small negative correlation between perceived stress and informational social support, $r(124)=-0.18, p=<0.05$. There was a negative correlation between perceived stress and emotional social support, esteem social support and tangible social support although these were not significant.

\section{Discussion}

The results indicated that athletes reported moderate levels of perceived stress, in line with previous research indicating that stress is a concern for a significant number of athletes [3-5]. The current research was interested in stress that athletes experienced in relation to their most recent sporting competition, which may explain the difference in the level of stress reported by the athletes in other studies. Other research in this area has identified that stress levels can be higher after competition rather than during training [7]. Female stress scores were significantly higher than the male athletes, similar to other research $[6,49,50]$. The gender differences in the findings is particularly interesting as the participants were all playing similar sports and this is one of the only studies that has been able to control for the sporting environment in this way.

Task orientated coping strategies were more frequently employed by the athletes during their previous match. Thought control was the most commonly used task oriented strategy, while resignation or disengagement was the least commonly reported, similar to previous findings with elite athletes $[18,30,51]$. Task orientated coping is argued to be particularly effective for managing stress in athletes as it involves taking specific action directed at managing the stressor [51]. In this respect the fact that the athletes in the current study were more likely to use these effective strategies may explain the moderate level of stress experienced and the avoidance of higher levels of stress.

The other frequently used task orientated coping strategies in the current research was mental imagery, a visualisation techniques that has been found to be used primarily by successful athletes to cope with stress [15,32]. Actions that reflect avoidant focused coping have been found to be effective coping strategy for athletes when they included venting and the use of humor [52]. However, venting were not found to be significantly associated with reduced stress in the current research, but interestingly was used more frequently than any of the other avoidant orientated strategies. All of the athletes sampled played team sports and therefore they may be more likely to discuss and share experiences with team mates and use venting as a way of coping with stress. In terms of the impact of these tasks orientated coping strategies, the research indicated a negative correlation between perceived stress and all of the task orientated strategies. Similar findings have been reported with mental imagery coping strategies associated with reduced experience of stress $[15,18]$.

There with a negative relationship observed between all four types of perceived social support and reported stress. This is similar to recent research highlighting the importance of this forms of social support on stress experienced in elite athletes [40,41,53]. This finding is particularly interesting as it suggests that in addition to individual coping mechanisms, the role of others in the athlete's life can be important in supporting HP athletes to deal with stressors and in particular may allow for the management of organisational stressors [12]. In the current study the athletes were encouraged to consider the social supports they perceived as available to them during the actual competition and this may explain why the highest reported levels of social support were informational, rather than emotional and esteem. All the athletes were playing team sports and the higher levels of informational support may be because of the fact they were playing within a team and other players were available to provide informational support to the athlete. This is similar to argument that coaches and 
Citation: McLean L, Penco R (2020) The Impact of Coping Strategies and Social Support on the Experience of Stress in High Performance Athletes. J Addict Addictv Disord 7: 43.

teammates provided support provided expertise and informational support for the athlete.

It could be argued that as these high performance athletes have access to other high performance athletes and to resources to help them with coping with stress. All athletes in the current athletes were involved in team sports and future research could compare these athletes to others. This may be particularly useful as Nixdrof et al. [54], has reported those involved in individual sports may have poorer coping strategies. As with all similar research in the area it could also be argued that there was the potential of the social desirability bias in the findings and the methodology including an emphasis placed on the anonymity of responses was an attempt to overcome this bias. The research was completed with a relatively small sample size but this is common in research with specific populations and with high performance/elite athletes. In all correlational study such as this one, the direction of the relationships between stress and coping cannot be confirmed. Further research with participants who have high reported levels of stress is needed to extend the understanding of the current findings.

Overall, the current findings indicates there are conditions that can moderate the experience of stress and strategies that can be developed to enable people to cope with stressors, even within high stress environments. In terms of coping with stressors, these athletes may have access to valuable resources that non athletes, or those performing at lower levels within sports do not have. HP athletes through their exposure to other elite athletes learn how to effectively cope with stressors and this might explain why in some studies they have been found to have higher levels of reactive stress tolerance than the general population [24]. Previous studies have consistently highlighted a significant causes of stress for high performance athletes related to informational and organisational stressors and the current research suggests that perceived social support may reduce and act as a buffer for those stressors [55-58].

In conclusion, the results from the current study are positive as they suggest that stress which is inherent within high performance sport is manageable. It also suggests that effective coping strategies are ones that can be developed by athletes. This links in with previous research suggesting that more resilient athletes may be more likely to use the more effective task orientated coping strategies to manage stress effectively $[59,60]$. The current research was designed to explore the ability of individuals who face a significant number of ongoing stressors to deal with these stressors and manage them in an effective way to allow them to continue to succeed and thrive. The ability to use effective task focused coping strategies and to access informational support appear to allow these athletes to manage these stressors effectively. These strategies are easily learnt and rehearsed, such as thought control, mental imagery and logical analysis and as such this is an optimistic finding within the field of wellbeing and the study of stress.

\section{References}

1. Slavich GM (2016) Life stress and health: A review of conceptual issues and recent findings. Teach Psychol 43: 346-355.

2. Stanton R, Reaburn P (2014) Exercise and the treatment of depression: A review of the exercise program variables. J Sci Med Sport 17: 177-182.
3. Losty C, Warrington G, Mc Goldrick A, Murphy C, Burrows E, et al (2019) Mental health and wellbeing of jockeys. Journal of Human Sport and Exercise 14: 147-158.

4. Davoren AK, Hwang S (2014) Mind, body and sport: Depression and anx iety prevalence in student-athletes: Understanding and supporting student-athletes mental wellness. NCAA, Indianapolis, USA.

5. Gustafsson H, Skoog T (2012) The meditational role of perceived stress in the relation between optimism and burnout in competitive athletes. Anxiety Stress Coping 25: 183-199.

6. Lee K, Kang S, Kim I (2017) Relationships among stress, burnout, athletic identity, and athlete satisfaction in students at Korea's physical education high schools: Validating differences between pathways according to ego resilience. Psychol Rep 120: 585-608.

7. Shearer D, Jones R, Kilduff L, Cook C (2015) Effects of competition on the sleep patterns of elite rugby union players. Eur J Sport Sci 15: 681-686.

8. Fullagar H, Skorski S, Duffield R, Julian R, Bartlett J, et al. (2016) Impaired sleep and recovery after night matches in elite football players. J Sports Sci 34: 1333-1339.

9. Smith LL (2003) Overtraining, excessive exercise and altered immunity Sports Med 33: 347-364.

10. Lavallee D (2012) Coping and Emotions in Sport. Nova Science Publishers, New York, USA.

11. Nicholls AR, Levy AR, Grice A, Polman RCJ (2009) Stress appraisals, coping, and coping effectiveness among international cross-country runners during training and competition. European Journal of Sport Science 9: 285-293.

12. Kristiansen E, Roberts GC (2010) Young elite athletes and social support: Coping with competitive and organizational stress in 'Olympic' competition. Scand J Med Sci Sports 20: 686-695.

13. Kristiansen E, Andersen SS, Hanstad DV (2013) The mundanity of Olympic housing: Norwegian athletes at the 2010 winter games. International Journal of Applied Sports Sciences 25: 147-158.

14. Anshel MH, Raviv S, Jamieson J (2001) Cognitive appraisals and coping strategies following acute stress among skilled competitive male and female athletes. Journal of Sport Behavior 24: 128.

15. Nicholls AR, Polman RCJ (2007) Coping in sport: A systematic review. J Sports Sci 25: 11-31.

16. Gustafsson H, Davis PA, Skoog T, Kenttä G, Haberl P (2015) Mindfulnes and its relationship with perceived stress, affect, and burnout in elite junior athletes. Journal of Clinical Sport Psychology 9: 263-281.

17. Duda JL, Gano-Overway L (1996) Anxiety in elite young gymnasts: Part II-sources of stress.

18. Fletcher D, Sarkar M (2012) A grounded theory of psychological resilience in Olympic champions. Psychology of sport and exercise 13: 669-678.

19. Wilson G, Pritchard M (2005) Comparing sources of stress in college student athletes and non-athletes. Journal of Sports Psychology 7: 1-8.

20. Landolt K, Maruff P, Horan B, Kingsley M, Kinsella G, et al. (2017) Chronic work stress and decreased vagal tone impairs decision making and reaction time in jockeys. Psychoneuroendocrinology 84: 151-158.

21. Hanton S, Fletcher D, Coughlan G (2005) Stress in elite sport performers: A comparative study of competitive and organizational stressors. J Sports Sci 23: 1129-1141.

22. Nicholls AR, Jones R, Polman RCJ, James DWG (2005) Stress and coping among international adolescent golfers. Journal of Applied Sport Psychology 17: 333-340 
Citation: McLean L, Penco R (2020) The Impact of Coping Strategies and Social Support on the Experience of Stress in High Performance Athletes. J Addict Addictv Disord 7: 43.

23. Watkins SL, Castle P, Mauger AR, Sculthorpe N, Fitch N, et al. (2014) The effect of different environmental conditions on the decision-making performance of soccer goal line officials. Res Sports Med 22: 425-437.

24. Ong N (2017) Reactive stress tolerance in elite athletes: Differences in gender, sport type, and competitive level. Cognitie Creier Comportament/ Cognition Brain Behavior 21: 189-202.

25. Abedalhafiz A, Altahayneh Z, Al-Haliq M (2010) Sources of stress and coping styles among student-athletes in Jordan universities. Procedia-social and behavioral sciences 5: 1911-1917.

26. Lemyre PN, Hall HK, Roberts GC (2008) A social cognitive approach to burnout in elite athletes. Scand J Med Sci Sports 18: 221-234.

27. Bennie A, Moran C (2013) The coach-athlete relationship in Australian touch football. Science and Football VII. Pg no: 361-367.

28. Humphrey JH, Yow DA, Bowden WW (2000) Stress in college athletics: Causes, consequences, coping. Haworth Press, Philadelphia, USA.

29. Gaudreau P, Blondin J (2004) Different athletes cope differently during a sport competition: A cluster analysis of coping. Personality and Individua Differences 36: 1865-1877.

30. Reeves WC, Nicholls RA, McKenna J (2011) The effects of a coping intervention on coping self-efficacy, coping effectiveness, and subject performance among adolescent soccer players. International Journal of Sports and Exercise Psychology 9: 126- 142.

31. Nicholls AR, Holt NL, Polman RCJ, Bloomfield J (2006) Stressors, coping, and coping effectiveness among professional rugby union players. The Sport Psychologist 20: 314-329.

32. Vealey RS, Greenleaf CA (2010) Seeing is believing: Understanding and using imagery in sport. In Williams JM (ed.). Applied sport psychology: Personal growth to peak performance. ( $\left.6^{\text {th }} \mathrm{edn}\right)$. McGraw-Hill, New York, USA.

33. Vidic Z, Martin MS, Oxhandler R (2018) Mindfulness meditation intervention with male collegiate soccer players: Effect on stress and various aspects of life. The Sport Journal 21

34. Morgan TK, Giacobbi PR (2006) Toward two grounded theories of the talent development and social support process of highly successful collegiate athletes. The Sport Psychologist 20: 295-313.

35. Freeman P, Rees T (2009) How does perceived support lead to better performance? An examination of potential mechanisms. Journal of Applied Sport Psychology 21: 429- 441.

36. Goodger K, Gorely T, Lavallee D, Harwood C (2007) Burnout in sport: A systematic review. The sport psychologist 21: 127-151.

37. Russell DW, Cutrona CE (1991) Social support, stress and depressive symptoms among the elderly: Test of a process model. Psychol Aging 6: 190-201.

38. Raedeke TD, Smith AL (2001) Development and preliminary validation of an athlete burnout measure. J Sport Exerc Psychol 23: 281-306.

39. Raedeke TD, Smith AL (2004) Coping resources and athlete burnout: An examination of stress mediated and moderation hypotheses. Journal of sport and exercise psychology 26: 525-541.

40. Holt NL, Hoar SD (2006) The Multidimensional Construct of Social Support. In Hanton S, Mellalieu SD (eds.). Literature Review in Sport Psychology. Nova Science Publishers, London, UK.

41. Crutcher B, Moran RN, Covassin T (2018) Examining the relationship between social support satisfaction and perceived stress and depression in athletic training students. Athletic Training Education Journal 13: 168-174.
42. DeFreese JD, Smith AL (2014) Athlete social support, negative social interactions and psychological health across a competitive sport season. J Sport Exerc Psychol 36: 619-630.

43. Freeman P, Coffee P, Rees T (2011) The PASS-Q: The perceived available supportin sport questionnaire. J Sport Exerc Psychol 33: 54-74.

44. DeFreese DJ, Smith LS (2013) Teammate social support, burnout, and self-determined motivation in collegiate athletes. Psychology of Sport and Exercise 14: 258-265.

45. Weston NJ, Thelwell RC, Bond S, Hutchings NV (2009) Stress and coping in single-handed round-the-world ocean sailing. Journal of Applied Sport Psychology 21: 460-474.

46. Cohen S, Kamarck T, Mermelstein R (1994) Perceived stress scale by Sheldon Cohen.

47. Gaudreau P (2001) Coping Inventory for Competitive Sports [CICS]. McGill University, Canada.

48. Cohen S, Kamarck T, Mermelstein R (1983) A global measure of perceived stress. J Health Soc Behav 24: 385-396.

49. Beable S, Fulcher M, Lee AC, Hamilton B (2017) SHARP sports mental health awareness research project: Prevalence and risk factors of depressive symptoms and life stress in elite athletes. J Sci Med Sport 20: 10471052 .

50. Schaal K, Tafflet, M, Nassif H, Thibault V, Pichard C, et al. (2011) Psychological balance in high level athletes: Gender-based differences and sport-specific patterns. PloS One 6: 19007.

51. Anshel MH, Delany J (2001) Sources of acute stress, cognitive appraisal, and coping strategies of male and female child athletes. Journal of Sport Behavior 24: 329-353.

52. Nicholls AR, Holt NL, Polman RCJ (2005) A phenomenological analysis of coping effectiveness in golf. The Sports Psychologist 19: 111-130.

53. Bianco T, Eklund RC (2001) Conceptual considerations for social support research in sport and exercise settings: The case of sport injury. Journal of sport and exercise psychology 23: 85-107.

54. Nixdorf I, Hautzinger M, Beckmann J (2013) Prevalence of depressive symptoms and correlating variables among German elite athletes. Journal of Clinical Sport Psychology 7: 313-326.

55. Dogan B (2009) Multiple-choice reaction and visual perception in female and male elite athletes. J Sports Med Phys Fitness 49: 91-96.

56. Donohue B, Miller A, Crammer L, Cross C, Covassin T (2007) A standardized method of assessing sport specific problems in the relationships of athletes with their coaches, teammates, family, and peers. Journal of Sport Behavior 30: 375-397.

57. Freeman P, Coffee P, Moll T, Rees T, Sammy N (2014) The ARSQ: The athletes' received support questionnaire. J Sport Exerc Psychol 36: 189202.

58. Hammermeister J, Burton D (2004) Gender differences in coping with endurance sport stress: Are men from mars and women from venus? Journal of Sports Behaviour 27: 148-164.

59. Secades XG, Molinero O, Salguero A, Barquin RR, de IV, et al. (2016) Relationship between resilience and coping strategies in competitive sport. Percept Mot Skills 122: 336-349.

60. Belem IC, Santos APDV, Caruzzo MN, Rigoni AGP, Both J, et al. (2017) What coping strategies are used for athletes of MMA more resilient to stress. Journal of Physical Education 8: 2448-2455. 


\section{If}

Advances In Industrial Biotechnology | ISSN: 2639-5665

Advances In Microbiology Research | ISSN: 2689-694X

Archives Of Surgery And Surgical Education | ISSN: 2689-3126

Archives Of Urology

Archives Of Zoological Studies | ISSN: 2640-7779

Current Trends Medical And Biological Engineering

International Journal Of Case Reports And Therapeutic Studies | ISSN: 2689-310X

Journal Of Addiction \& Addictive Disorders | ISSN: 2578-7276

Journal Of Agronomy \& Agricultural Science | ISSN: 2689-8292

Journal Of AIDS Clinical Research \& STDs | ISSN: 2572-7370

Journal Of Alcoholism Drug Abuse \& Substance Dependence | ISSN: 2572-9594

Journal Of Allergy Disorders \& Therapy | ISSN: 2470-749X

Journal Of Alternative Complementary \& Integrative Medicine | ISSN: 2470-7562

Journal Of Alzheimers \& Neurodegenerative Diseases | ISSN: 2572-9608

Journal Of Anesthesia \& Clinical Care | ISSN: 2378-8879

Journal Of Angiology \& Vascular Surgery | ISSN: 2572-7397

Journal Of Animal Research \& Veterinary Science | ISSN: 2639-3751

Journal Of Aquaculture \& Fisheries | ISSN: 2576-5523

Journal Of Atmospheric \& Earth Sciences | ISSN: 2689-8780

Journal Of Biotech Research \& Biochemistry

Journal Of Brain \& Neuroscience Research

Journal Of Cancer Biology \& Treatment | ISSN: 2470-7546

Journal Of Cardiology Study \& Research | ISSN: 2640-768X

Journal Of Cell Biology \& Cell Metabolism | ISSN: 2381-1943

Journal Of Clinical Dermatology \& Therapy | ISSN: 2378-8771

Journal Of Clinical Immunology \& Immunotherapy | ISSN: 2378-8844

Journal Of Clinical Studies \& Medical Case Reports | ISSN: 2378-8801

Journal Of Community Medicine \& Public Health Care | ISSN: 2381-1978

Journal Of Cytology \& Tissue Biology | ISSN: 2378-9107

Journal Of Dairy Research \& Technology | ISSN: 2688-9315

Journal Of Dentistry Oral Health \& Cosmesis | ISSN: 2473-6783

Journal Of Diabetes \& Metabolic Disorders | ISSN: 2381-201X

Journal Of Emergency Medicine Trauma \& Surgical Care | ISSN: 2378-8798

Journal Of Environmental Science Current Research | ISSN: 2643-5020

Journal Of Food Science \& Nutrition | ISSN: 2470-1076

Journal Of Forensic Legal \& Investigative Sciences | ISSN: 2473-733X

Journal Of Gastroenterology \& Hepatology Research | ISSN: 2574-2566
Journal Of Genetics \& Genomic Sciences | ISSN: 2574-2485

Journal Of Gerontology \& Geriatric Medicine | ISSN: 2381-8662

Journal Of Hematology Blood Transfusion \& Disorders | ISSN: 2572-2999

Journal Of Hospice \& Palliative Medical Care

Journal Of Human Endocrinology | ISSN: 2572-9640

Journal Of Infectious \& Non Infectious Diseases | ISSN: 2381-8654

Journal Of Internal Medicine \& Primary Healthcare | ISSN: 2574-2493

Journal Of Light \& Laser Current Trends

Journal Of Medicine Study \& Research | ISSN: 2639-5657

Journal Of Modern Chemical Sciences

Journal Of Nanotechnology Nanomedicine \& Nanobiotechnology | ISSN: 2381-2044

Journal Of Neonatology \& Clinical Pediatrics | ISSN: 2378-878X

Journal Of Nephrology \& Renal Therapy | ISSN: 2473-7313

Journal Of Non Invasive Vascular Investigation | ISSN: 2572-7400

Journal Of Nuclear Medicine Radiology \& Radiation Therapy | ISSN: 2572-7419

Journal Of Obesity \& Weight Loss | ISSN: 2473-7372

Journal Of Ophthalmology \& Clinical Research | ISSN: 2378-8887

Journal Of Orthopedic Research \& Physiotherapy | ISSN: 2381-2052

Journal Of Otolaryngology Head \& Neck Surgery | ISSN: 2573-010X

Journal Of Pathology Clinical \& Medical Research

Journal Of Pharmacology Pharmaceutics \& Pharmacovigilance | ISSN: 2639-5649

Journal Of Physical Medicine Rehabilitation \& Disabilities | ISSN: 2381-8670

Journal Of Plant Science Current Research | ISSN: 2639-3743

Journal Of Practical \& Professional Nursing | ISSN: 2639-5681

Journal Of Protein Research \& Bioinformatics

Journal Of Psychiatry Depression \& Anxiety | ISSN: 2573-0150

Journal Of Pulmonary Medicine \& Respiratory Research | ISSN: 2573-0177

Journal Of Reproductive Medicine Gynaecology \& Obstetrics | ISSN: 2574-2574

Journal Of Stem Cells Research Development \& Therapy | ISSN: 2381-2060

Journal Of Surgery Current Trends \& Innovations | ISSN: 2578-7284

Journal Of Toxicology Current Research | ISSN: 2639-3735

Journal Of Translational Science And Research

Journal Of Vaccines Research \& Vaccination | ISSN: 2573-0193

Journal Of Virology \& Antivirals

Sports Medicine And Injury Care Journal | ISSN: 2689-8829

Trends In Anatomy \& Physiology | ISSN: 2640-7752

Submit Your Manuscript: https://www.heraldopenaccess.us/submit-manuscript 